\title{
The evolutionary transformation of modern agri-food systems: emerging trends in consumption, production, and in the provision of public goods
}

\author{
Luca Camanzi ${ }^{1}$ and Stefania Troiano $2^{2^{*}}$
}

\footnotetext{
* Correspondence: stefania.troiano@ uniud.it

${ }^{2}$ Department of Economics and Statistics, University of Udine, via Tomadini, 30/a, 33100 Udine, Italy Full list of author information is available at the end of the article
}

\section{Background}

Agriculture and more in general modern agri-food supply systems and networks are called to satisfy a number of consumers' needs and to create value to the benefit of the whole society. In fact, they are expected to ensure enterprise profitability, supply chain coordination, providing quality products, as well as enhancing health conditions, environmental protection, and wider social values. At the same time, they have to tackle global drivers, which could produce both opportunities and negative impacts on local resources and development trends. Among these aspects, climate change and natural resource conservation have influenced agricultural production methods and the trend toward an increased environmental sustainability will continue producing a "transition towards greener rural economies" in the future (European Union 2017).

An improvement of the multifunctional role of agriculture will be driven by technological transformations and innovations including the relationship between environmental resources management and agricultural activities.

Moreover, food production and consumption are transforming rapidly. On the one hand, the aim of reaching both food security and safety are big global challenges; on the other hand, food waste and losses are also phenomena that need to be addressed both at local and global levels.

Furthermore, the affirmation of conscious and responsible consumption models offers new opportunities for sustainability enhancement, both at local and global scale. In addition, it is necessary to take into consideration the role that agriculture can play within an alternative, not conventional linear economic model, such as a circular economy.

The main issues raised by such an evolutionary scenario relate to the use of natural resources, biodiversity conservation, food safety and quality enhancement, business model innovation, sectoral and fiscal policies as well as private-public coordination

(c) The Author(s). 2021 Open Access This article is licensed under a Creative Commons Attribution 4.0 International License, which permits use, sharing, adaptation, distribution and reproduction in any medium or format, as long as you give appropriate credit to the original author(s) and the source, provide a link to the Creative Commons licence, and indicate if changes were made. The images or other third party material in this article are included in the article's Creative Commons licence, unless indicated otherwise in a credit line to the material. If material is not included in the article's Creative Commons licence and your intended use is not permitted by statutory regulation or exceeds the permitted use, you will need to obtain permission directly from the copyright holder. To view a copy of this licence, visit http://creativecommons.org/licenses/by/4.0/. 
strategies, supporting the development of agri-food systems, across the four main axes of sustainability, i.e., its economic, social, environmental and cultural dimensions (United Nations 2014).

The 55th annual conference of the Italian Society of Agricultural Economics (SIDE A), titled "Green metamorphoses: agriculture, food, ecology" that was held in Perugia on 13-15 September 2018 offered the opportunity for a scientific debate among agricultural economists and sociologists on the deep transformations that are affecting modern agri-food systems (Torquati and Marchini 2020).

In fact, the two main plenary sessions of the Conference considered: (i) the challenges faced by agricultural enterprises and public policies to meet the need for food, health, and civic responsibility in modern society and related theories and (ii) climate change adaptation theories, assessment methods, and empirical results. Around these plenary sessions, many invited papers were presented to face the theme of the conference from different theoretical and empirical standpoints.

Among these, five papers have been selected for this special issue, aiming to bridge the still-too-wide gaps that separate knowledge and implementation. In these articles, the authors have described and analyzed a number of opportunities for agricultural activities, food production and consumption, and environmental resources to move towards sustainability.

\section{This special issue}

The research papers included in this special issue provide a broad view of the ongoing scientific debate on the topics mentioned above. Mainly using surveys and case studies along the agri-food supply chain, the studies offer new insights into various aspects ranging from food consumption and production to environmental resources management.

Two articles investigate the emerging trends in conscious and responsible food consumption. Specifically, the study conducted by Marchini et al. titled "Label information and consumer behaviour: evidence on drinking milk sector", evaluates consumer behavior and interest towards the label information, based on the inclusion of different types of information, i.e., mandatory vs voluntary disclosures. Interestingly, in this study consumer behavior is modeled based on a neo-institutional approach and nutrition, origin, processing technology, animal feed, and environmental sustainability attributes of drinking milk are considered as part of the multidimensional nature of the quality concept. Then, an ordered logit model is estimated and the empirical results obtained point out the tradeoff between the costs and benefits ensuing from the reduction of information asymmetries. The authors argue that, while quality disclosures represent a cost for producers, they have the potential to increase consumer appreciation and to reduce frauds in the drinking milk sector.

A second aspect of great interest in the recent academic literature on consumer behavior is the moderating role of the organic certification on consumer appreciation of food product quality. The paper by Boncinelli et al. focuses on this issue with regards to wine purchases, evaluating the possible presence of attribute non-attendance (ANA) behavior (the situation in which consumers pay attention only to some attributes without taking other attributes into consideration). Based on the results of a choice experiment, the authors found that a significant proportion of buyers prefers organic wine and they suggest that the hypothesis of consumers rationality-i.e., that they process all 
the information available, when purchasing wine, should be relaxed. More in detail, most consumers do not pay attention to the organic certification, demonstrating that they focused on other wine attributes. These results have relevant implications for future research and for marketing. In fact, ignoring the presence of this behavior might lead to distorted estimates of purchasing parameters and consumers' willingness to pay. As a second implication, the authors suggest that the wine market is not split between conventional wine consumers and organic wine consumers. On the opposite, it is possible to adopt marketing strategies exploiting the potential of the attributes which consumers are interested in, that being for example other production methods or other quality features.

Further topical issues addressed by the contributed papers included in this special issue relate to the adoption of sustainable production practices and the provision of public goods in modern agri-food systems.

A preliminary step towards the implementation of a virtuous circular economy entails the possibility to measure the degree of circularity in order to better understand and improve production processes. In the study titled "Measuring circularity: an application of modified Material Circularity Indicator to Agricultural system" Rocchi et al. aim to demonstrate the capability to measure circularity of a product, a supply chain or a service could be useful for driving policies and achieving a higher level of sustainability. Considering the Circular Economy paradigm, the biological cycles are mainly connected to the agricultural sector and for this kind of cycles the lack of measurement is even bigger. Among agricultural productions, a number of them have a linear structure (e.g., intensive meat production), which results in a percentage of waste. The authors propose a modification of the Material Circularity Indicator (MCI) to adapt to the biological cycles. This tool was applied to the poultry sector, integrating the results with the Life Cycle Assessment method.

The role of collective action in providing public goods is fundamental. Moreover, the participative process is indispensable for understanding common identity elements, while the knowledge of the territorial capital contributes to the activation of forms of collective intelligence necessary for decision-making processes. In their contribution, titled "Commoning of territorial heritage and tools of participated sustainability for the production and enhancement of agro-environmental public goods", Safonte et al. offer an analysis of how the commoning heritage processes have found application for the production of agro-environmental public goods in contexts of high socio-economic marginality and environmental vulnerability, characterized by abandonment and from the consumption of agricultural land for food use. By developing a model useful to the understanding of the unfolding of complexity, the Authors point out the importance of the concept of territory, as perceived in its procedural dimension of long duration and as a result of the meeting between the tangible and intangible elements of the territorial capital as a whole, in which the aspects of environmental endowment play a crucial role. In addition, the findings of the study show the key role played by the improvement of the decision-making process and the relative ability to think and to formulate policy actions.

Periurban farming has been a key characteristic for another subfield of agricultural transition toward sustainability. According to Gaviglio et al. periurban farming systems are characterized by the need to adapt the farming practices coping with a modified 
natural and social environment pointing out questions about the efficient use of the inputs. In the study titled "Technical Efficiency and Productivity of farms: a periurban case study analysis" the Authors employ a Data Envelopment Analysis to capture the heterogeneity of periurban farming systems. A survey was carried out among farms located in the South Milan Agricultural Park and findings show firstly that crops farms are more efficient than livestock farms although they have a less productive technology, secondly it seems that the participation in short food supply chains and the multifunctional agriculture do not affect the levels of technical efficiency. The results point out the role of policies in improving the educational level of farmers and supporting farms' efficiency.

\section{Conclusions}

The papers included in this special issue offer topical and original insights on the evolutionary transformation of modern agri-food systems, addressing emerging trends on various aspects related to consumer awareness and food quality appreciation, to the adoption of sustainable production practices and the provision of public goods in modern agri-food systems.

The key message supported by these papers is that the systemic transformation underway requires a reconsideration of how agricultural goods are produced and consumed in order to reduce the negative environmental impacts of agri-food systems, to protect nature and biodiversity, to improve their resilience against crises, while guaranteeing that healthy and affordable food is available for people today and for tomorrow's generations.

From a methodological perspective, this implies a strong emphasis on the need to develop interdisciplinary approaches to further enhance the understanding of the complex dynamics that are taking place and to provide effective guidance and actionable tools to all the stakeholders and sectoral policy makers.

From a policy perspective, it is worth noticing that the work of the researchers attending the LV SIDEA Conference was essentially anticipating the recent EU "Farm to Fork" Strategy whose aim is to "address comprehensively the challenges of sustainable food systems and recognizes the inextricable links between healthy people, healthy societies and a healthy planet" (European Commission 2020).

These considerations underline the validity of the research activity already conducted in the past, as well as the responsibility for the guidance that agricultural economists will offer in the future, for the benefit of agri-food sector stakeholders and the entire society.

The authors would like to thank the Agricultural and Food Economics Journal for having given visibility to the papers presented at the $55^{\text {th }}$ SIDEA Conference, supporting the international diffusion of the debate developed by Italian agricultural economists.
}

Authors' contributions

LC participated in the design of the manuscript and in the development of the report section and drafted the conclusions. ST participated in the design of the manuscript and in the development of the report section and drafted the background section. Both authors read and approved the final manuscript.

\section{Declarations}


Author details

${ }^{1}$ Department of Agricultural and Food Sciences, Alma Mater Studiorum - Università di Bologna, viale G. Fanin, 50, 40127 Bologna, Italy. ²Department of Economics and Statistics, University of Udine, via Tomadini, 30/a, 33100 Udine, Italy.

Published online: 14 June 2021

\section{References}

European Commission (2020) Communication from the Commission to the European Parliament, the Council, the European Economic and Social Committee and the Committee of the Regions: A Farm to Fork Strategy for a fair, healthy and environmentally-friendly food system COM/2020/381 final.

European Union (2017) Transition to Greener Rural Economies. European Network for Rural Development, Luxembourg https://enrd.ec.europa.eu/

Torquati B, Marchini A (eds) (2020) Green metamorphoses: agriculture, food, ecology. Proceedings of the LV Conference of SIDEA Studies. Wageningeen Academic Publishers, Wageningeen p 492. https://doi.org/10.3920/978-90-8686-898-8

United Nations (2014) Prototype Global Sustainable Development Report (Online unedited ed.). United Nations Department of Economic and Social Affairs, Division for Sustainable Development, New York http://sustainabledevelopment.un.org/ globalsdreport/

\section{Publisher's Note}

Springer Nature remains neutral with regard to jurisdictional claims in published maps and institutional affiliations.

Submit your manuscript to a SpringerOpen ${ }^{\circ}$ journal and benefit from:

- Convenient online submission

- Rigorous peer review

- Open access: articles freely available online

- High visibility within the field

- Retaining the copyright to your article

Submit your next manuscript at $\boldsymbol{\nabla}$ springeropen.com 